\title{
Management of rare diseases of the Head, Neck and Teeth: results of a French population-based prospective 8-year study
}

Lisa Friedlander ${ }^{1,2^{*}}$ (D), Rémy Choquet ${ }^{3}$, Eva Galliani ${ }^{4,5,6}$, Myriam de Chalendar $^{7}$, Claude Messiaen ${ }^{3}$, Amélie Ruel $^{3}$, Marie-Paule Vazquez ${ }^{4,5,6,7}$, Ariane Berdal ${ }^{2,8}$, Corinne Alberti ${ }^{1}$ and Muriel De La Dure Molla ${ }^{2,9}$

\begin{abstract}
Background: In the last ten years, national rare disease networks have been established in France, including national centres of expertise and regional ones, with storage of patient data in a bioinformatics tool. The aim was to contribute to the development and evaluation of health strategies to improve the management of patients with rare diseases. The objective of this study has been to provide the first national-level data concerning rare diseases of the head, neck and teeth and to assess the balance between demand and supply of care in France.

Methods: Centres of expertise for rare diseases record a minimum data set on their clinical cases, using a list of rare Head, Neck and Teeth diseases established in 2006. The present analysis focuses on 2008 to 2015 data based on the Orphanet nomenclature. Each rare disease RD "case" was defined by status "affected" and by the degree of diagnostic certainty, encoded as: confirmed, probable or non-classifiable. Analysed parameters, presented with their 95\% confidence intervals using a Poisson model, were the following: time and age at diagnosis, proportions of crude and standardized RD prevalence by age, gender and geographical site. The criteria studied were the proportions of patients in Paris Region and the "included cases geography", in which these proportions were projected onto the other French Regions, adjusting for local populations.
\end{abstract}

Results: In Paris Region, estimated prevalence of these diseases was 5.58 per 10,000 inhabitants (95\% Cl 4.3-7.1). At December 31st 2015, 11,342 patients were referenced in total in France, of whom 7294 were in Paris Region. More than 580 individual clinical entities (ORPHA code) were identified with their respective frequencies. Most abnormalities were diagnosed antenatally. Nearly $80 \%$ of patients recorded come to Paris hospitals to obtain either diagnosis, care or follow up. We observed that the rarer the disease, the more patients were referred to Paris hospitals.

Conclusions: A health network covering a range of aspects of the rare diseases problematic from diagnostics to research has been developed in France. Despite this, there is still a noticeable imbalance between health care supply and demand in this area.

Keywords: Rare diseases, Registry, Epidemiology, Orofacial diseases, Oral cleft

\footnotetext{
* Correspondence: lisa.friedlander@inserm.fr

'Université Paris Diderot - Sorbonne Paris Cité, INSERM, Laboratoire ECEVE

UMR1123, Paris, France

${ }^{2}$ Centre de référence des malformations rares de la face et de la cavité

buccale, Hôpital Rothschild, AP-HP, Paris, France

Full list of author information is available at the end of the article
} 


\section{Background}

To be considered as rare, an individual disease must affect a limited number of people within the population. It is defined, in Europe, by a prevalence lower than 1 per 2000 (European Regulations on Orphan Medicine) [1].

More than 7000 such clinical entities have been described of which between 70 and $80 \%$ are genetic [2]. In the Orphanet database [3], rare Head and Neck disorders comprise 2153 diseases [4]. These include rare facial disorders (such as lip and cleft palate, isolated or associated with syndromes like Goldenhar syndrome or van der Woude syndrome), oral and dental disorders (such as isolated oligodontia or associated with syndromes such as ectodermal dysplasia), ORL disorders (such as cervicofacial fistulas associated with BOR syndrome), and cranial disorders (such as craniofaciosynostosis associated for example with Crouzon syndrome).

These rare diseases may be life threatening, cause growth disorders, and impose an economic and social burden because of their repercussions on psychological and physiological growth $[5,6]$. Many syndromes present facial anomalies. For some of these anomalies no treatment is required, for example hypertelorism, but for many others surgery is necessary to restore appearance and function $[7,8]$. Facial dismorphologies have repercussions for oral functions: breathing, chewing, deglutition, phonation, smiling, mimicking and facial expressions. Sensory deficit can be observed affecting auditory, olfactory and visual capacities. All of these severe health problems generate situations of functional handicap. Moreover, facial appearance negatively impacts the quality of life of patients and their families. Psychological and emotional suffering and social difficulties affecting school life and professional integration are frequently reported $[9,10]$. The rarity and the complexity of these diseases also cause some other difficulties, such as access to diagnosis and care [11].

Orofacial functions belong to the first stage of physiological and primary needs. They are essential to daily wellbeing and are prior to the needs for security, belonging, self-esteem and achievement [12]. For these reasons, it is essential that these diseases are properly and collectively managed throughout the lifetime following the evolving needs of patients. Given the variety of genotypes and treatments, this implies an integrated network of practitioners including geneticists, biologists, surgeons, paediatricians, orthodontists, dental surgeons, speech-language pathologists and psychologists. The care pathway of most of these diseases often begins with surgery. There may be reiterative surgical procedures in the early years of life and even during the teenage and young adult phase [13-15]. Parents with children suffering from rare diseases regularly express concerns about the long-term health outcomes for children who are born with an oral cleft, for example [16, 17]. Existing studies on Head, Neck and Teeth RD are often case reports and/or gene mutation reports for one disease. Very few studies have been published based on population-level data collection. There are existing epidemiological studies, based on large cohorts in Ethiopia and UK [18, 19], of the most frequent RD (when these are grouped together) such as oral cleft $[18,19]$. In France there are regional data but no presently available national-level data on these diseases [20].

The RD Healthcare network in France was first organized in 2005. The Head, Neck and Teeth National Network is one of the 23 French RD healthcare networks created under the national policy on RD (http://www.orpha.net/ actor/EuropaNews/2006/doc/French_National_Plan.pdf. One hundred and thirty-one expertise centres called reference centres for RD have been established in France, creating highly specialised university and non-university hospital teams for diagnosis and care. A national repository of data on patients with rare diseases, referred to centres involved in one of the rare disease networks, was established during the second French national plan. It is called BNDMR (Banque Nationale de Données Maladies Rares) (http:// enlord.bndmr.fr/\#homepage). Each sector includes RD reference centres and RD competence centres. Centres of expertise are called centres of reference in France, and the regional centres are called competence centres. Reference centres are intended to coordinate the definition of referential and therapeutic protocols as well as epidemiological supervision and education and research activities. At regional level, the competence centres identified by the reference centres establish the diagnoses of rare diseases, implement therapies when available, and organise patient care in relation to the designated reference centres and actors, and health and medico-social structures [21]. Reference and competence centres work with many health facilities, through diagnostic laboratories, medico-social professionals, fundamental, clinical and translational research teams, and patient associations.

Data collected from these centres are recorded in The French Rare Diseases Repository (BNDMR) with the following objectives:

1) To measure and describe the time taken to diagnose and therapeutic care. The purpose is to be able to prioritise actions to facilitate the orientation of patients in the health system when there is no specific reference centre for the concerned or suspected rare disease.

2) To improve the continuity between the actors involved in medical care, diagnostic innovation and therapeutic research.

The objective of the present study was to describe and analyse the relationship between the supply and the demand for care. The first aim was to describe the healthcare services available at regional and national levels for 
people suffering from these diseases. A second aim was to assess the level of access to care for these diseases through the national network. Observations at regional and national levels are presented here to better understand the patient care pathway within this specific network.

\section{Methods}

\section{Study design}

This was a prospective population-based study. Data were entered into the BNDMR prospectively using the CEMARA software [22]. A minimum data set (MDS) to be collected for each patient with a rare disease has been defined [23] (see Additional file 1).

This MDS was defined following a long process involving health professionals of the reference centres for RD and a ministerial working group. The MDS aims to minimize the amount of data collected by a centre while guaranteeing the quality of information collected and its exploitation. It supports communication with the information systems of hospital care. It thus constitutes a base of information common to all the uncommon diseases and all the actors involved in their care [22]. The national MDS for RD is constructed in the following way: assent/ consent (regulatory), national identification of patients, personal information, family information, vital status, course of care, activity of care, history of disease, diagnosis, confirmation of the diagnosis, treatment, ante and neonatal data, research protocol, structure of care.

\section{Inclusion criteria}

For this study, 2008-2015 data were used [22]. All patients with a head, neck or teeth RD confirmed as diagnosed by the RD network were included, with coding using the Orphanet nomenclature and/or a description of chromosomal abnormalities [24].

A "case" was defined as a patient with diagnostic certainty followed up in a RD reference centre. In some cases, tele-expertised cases may be reported and also expert opinion on medical files. Patients may be underreported, as not all patients are referred to a centre of the network.

\section{The care network}

\section{National health network}

National network of centres of expertise for patients with head and neck rare diseases includes six Reference Centres (Paris (4), Lille (1) and Strasbourg (1)) and 34 Competence Centres in 18 French cities. In Paris Region, four reference centres and no competence centres exist (Fig. 1). We first analysed data from all the centres. Then, to assess the balance between demand for and supply of care, we analysed data in two of the Paris reference centres, MAFACE (specialized in orofacial diseases) and MALO (specialized in othorynolaryngology).
These two centres were highlighted for this analysis because they offer the most comprehensive and therefore representative data on their activity.

\section{Users}

In $\mathrm{RD}$ centres, data were coded by all the practitioners involved in care, and by non-medical staff (psychologists, speech therapists...), and were entered by medical secretaries.

\section{Regulatory approval}

The database was previously approved by national authorities (CCTIRS and CNIL) under authorisation number: 1187326. Patients identified in the database were informed that their data could be used for research purpose.

\section{Statistical method}

For this study analysis, nominative data captured were de-identified [22, 25]. An anti-duplicate device was set up automatically.

To guarantee an optimal control of the data quality, automated completeness and consistency checks were implemented. BNDMR data-managers routinely perform "queries" on themes of consistency. To verify the quality of data, the script is checked on a weekly basis by BNDMR computer scientists entirely devoted to this task. Duplicates are systematically sought and missing data in the minimal data set are verified. Each numeric variable has unauthorised values (e.g., birth date or aberrant birth weight). There are also boundaries for each numerical variable (eg a patient's date of birth may not be later than the present day).

Data analysed were, first, population descriptions for the French regions and Paris Region (age, sex, abnormalities diagnosed), time and age at first signs, time and age at diagnosis. Next, supply of care was described (type of consultations, patient's reference).

Two measures were performed:

- The proportion of patients in French regions was evaluated as follows: people living in the region and registered in this region during the study period (patients seen in the reference/competence centres for one of the diseases and described as living in the region) are called "patients". The proportion was calculated as follows: $\mathrm{P}=$ (patient living in the region and registered in the database during the study time)/(population in the region).

- Second measure: "included cases geography".

In order to detect possible health service provision issues, we supposed that the Paris regional data can be used as a model to project onto other regions to estimate the number of rare Head, Neck and Teeth 


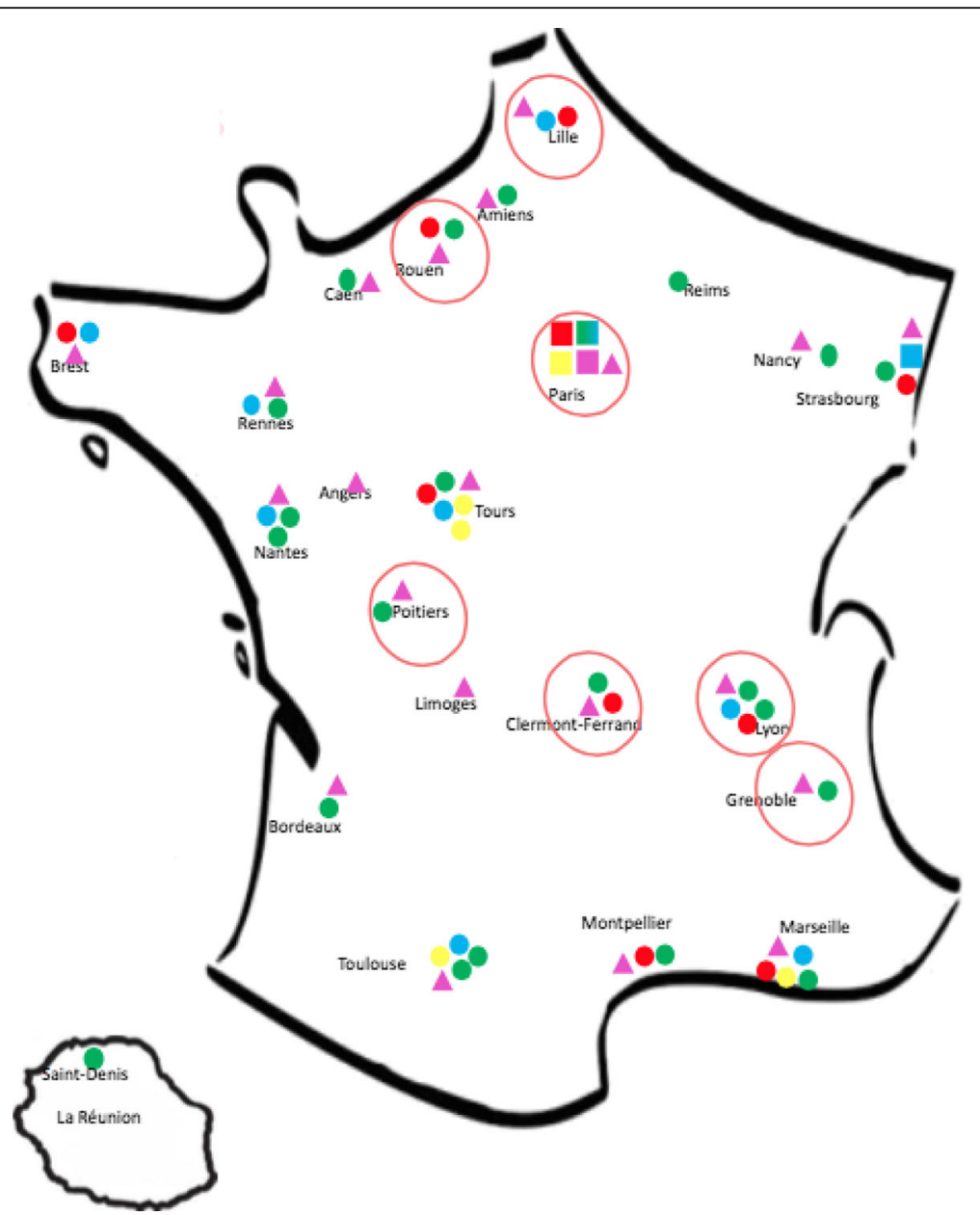

Fig. 1 Head, Neck Teeth French Network. $\bigcirc$ CEMARA USERS. $\square$ Reference centers. $\square$ Severe ENT Malformations competence centers. Severe Craniofacial malformations competence centers. $\square$ Cleft lip and palate competence centers. $\square$ Rare dental Malformations competence centers.

Reference centers "Pierre Robin"

rare diseases patients. This procedure was justified by the fact that there is no scientific proof that these diseases are, in France, related to the area of residence. Moreover, Paris is the capital of the country with many university hospitals; it is the place of choice to seek care. We standardised the Paris Region proportions onto the other French regions, adjusting for local populations. We calculated an observed proportion and an expected proportion for each region. The ratio of these proportions provides information about the numbers of patients who leave their region to find treatment in Paris Region.

The proportions of crude and standardised RD prevalence based on age, gender and national and regional localisation, have been presented with 95\% confidence intervals using a Poisson model. An analysis of the distance between the place of residence and the treatment site was carried out, and the time to diagnosis for patients without confirmed diagnosis was assessed.
The statistical software used is $\mathrm{R}$ for Windows, version 3.3.2.

\section{Results}

\section{Population description}

During the period from January 2008 to December 2015, 11,342 patients in France were diagnosed with RD and entered in the database. Seventy two thousand nine hundred four of these patients were coded in the Paris Region, and 4048 outside of Paris/other French regions (Table 1).

Abnormalities were diagnosed antenatally for $34.7 \%(n=$ 1142) of patients in other French regions and 29.7\% ( $n=$ 1480) of patients in Paris Region (Table 1).

\section{Diagnosis}

There were 520 clinical entities diagnosed (ORPHA code numbers) in other French regions and 462 in Paris Region. Estimated prevalence for all these diseases was 1.6 per 10,000 inhabitants (95\% CI 1.0-2.5) in other French 
Table 1 Population description

\begin{tabular}{lll}
\hline Characteristics & Patients (national except Paris Region) $n=4048$ & Patients (Paris Region) $n=7294$ \\
\hline Age (years), median & 7 & 6 \\
$\quad$ (Minimum-maximum) & $(0-55)$ & $(0-55)$ \\
Sex, $\mathrm{n}=$ & 4015 & 7192 \\
Male & $2160(53.8)$ & $3569(49.6)$ \\
Female & $1855(46.2)$ & $3623(50.4)$ \\
Abnormalities diagnosed antenatally, $n=$ & 3290 & 4989 \\
No & $2148(65.3)$ & $3509(70.3)$ \\
Yes & $1142(34.7)$ & $1480(29.7)$ \\
Other diagnoses, $n$ & 520 & 462 \\
\hline
\end{tabular}

regions, and 5.1 per 10,000 inhabitants (95\% CI 3.9-6.6) in Paris Region.

As shown in Table 2, the five most frequent diseases of the pathway were cleft lip and alveolus ( $n=2059,18.1 \%)$, cleft palate $(n=1799,15.9 \%)$, vascular anomaly or angioma $(n=964,8.5 \%)$, isolated Pierre Robin Syndrome $(n=$ $883,7.8 \%)$ and cleft hard palate $(n=688,6.1 \%)$.

Time of diagnosis was mostly antenatal for cleft lip and alveolus, with $39.5 \%$, and $27.0 \%$ in other French regions and Paris Region respectively. Diagnosis of Isolated Pierre Robin Syndrome was at birth for 56.0\% and 35.0\% in the two areas. It was postnatal for $15.1 \%(n=405)$ and $24.8 \%(n=642)$ (Table 2).

The median age of patients at the time of diagnosis depended on the disease. For cleft lip and alveolus, median age was 55 months in the other French regions and at birth for Paris Region. For cleft palate, it was 30 months for other French regions and 4 months for Paris Region. For Isolated Pierre Robin Syndrome, it was nearly the same: 2 months and 2.5 months respectively in other French regions and Paris Region. For cleft hard palate, it was 24 months for other French regions and 3.5 months for Paris Region (Table 2).

\section{Supply of care}

As shown in Table 3, among the different objectives of patient consultations are follow-up, global care, diagnosis, medical, emergency, prenatal diagnosis and research.

Follow-up consultations represent $55.5 \%(n=7463)$ of consultations in the other French regions and 71.8\% ( $n=$ 20,560) in Paris Region (Table 3).

In terms of references, we show that patients were largely referred by paediatricians $(45.6 \%, n=1849$ in other French regions and $40.9 \%, n=2986$ in Paris Region) but also by patient associations $(1.5 \%, n=62$ in other French regions and $0.4 \%, n=31$ in Paris Region), or by another medical specialist $(20.8 \%, n=843$ in other French regions and $32.6 \%, n=2381$ in Paris Region) (Table 3).

Some patients referred themselves or presented with a parent $(7.9 \%, n=323$ in other French regions and 10.9\%, $n=798$ in Paris Region) (Table 3).

\section{Balance between demand for and supply of care}

The care pathway of patients from French regions for treatment in Paris was analysed (Fig. 2). The figure shows the path taken by patients to seek treatment in reference and

Table 2 Time and age at diagnosis of the 5 more frequent diseases of the network (French regions And Paris Region)

\begin{tabular}{|c|c|c|c|c|c|c|c|c|c|c|c|}
\hline \multirow[t]{2}{*}{ Disease } & \multirow[t]{2}{*}{ N (\%) } & \multirow[t]{2}{*}{ Location } & \multirow[t]{2}{*}{ n (\%) } & \multicolumn{3}{|c|}{ Time at diagnosis } & \multicolumn{5}{|c|}{ Age at diagnosis (months) } \\
\hline & & & & Antenatal & birth & Postnatal & Min. & 1st Qu. & Median & 3rd Qu. & Max. \\
\hline Cleft lip and alveolus & 2059 (18.1\%) & French Regions & $954(16.8)$ & 39.5 & 18.7 & 0.2 & 36.0 & 45.5 & 55.0 & 64.5 & 74.10 \\
\hline 141,291 & & Paris Region & 1105 (13.6) & 27.0 & 3.7 & 0.0 & 0.0 & 0.0 & 0.0 & 0.0 & 0.0 \\
\hline Cleft palate & 1799 (15.9\%) & French Regions & $731(12.9)$ & 10.5 & 34.3 & 1.5 & 1.0 & 7.5 & 30.0 & 39.0 & 60.0 \\
\hline 2014 & & Paris Region & $1068(13.1)$ & 15.8 & 8.9 & 0.5 & 1.0 & 1.0 & 4.0 & 18.5 & 120.0 \\
\hline Vascular anomaly or angioma & $964(8.5 \%)$ & French Regions & $148(2.6)$ & 0.0 & 3.4 & 0.7 & $N / A^{*}$ & N/A & N/A & N/A & N/A \\
\hline 68,419 & & Paris Region & $816(10.0)$ & 0.0 & 1.8 & 1.7 & 0.0 & 1.0 & 1.0 & 3.5 & 36.0 \\
\hline Isolated Piere Robien Syndrome & $883(7.8 \%)$ & French Regions & $318(5.6)$ & 7.2 & 56.0 & 1.9 & 2.0 & 2.0 & 2.5 & 32.25 & 120.0 \\
\hline 718 & & Paris Region & $565(7.0)$ & 5.1 & 35.0 & 1.4 & 0.0 & 1.5 & 2.0 & 13.0 & 48.0 \\
\hline Cleft hard palate & $688(6.1 \%)$ & French Regions & $393(6.9)$ & 9.1 & 62.3 & 4.3 & 1.0 & 2.5 & 24.0 & 51.0 & 324.0 \\
\hline 101,023 & & Paris Region & $295(3.6)$ & 16.9 & 6.4 & 0.7 & 1.0 & 2.25 & 3.5 & 4.75 & 6.0 \\
\hline
\end{tabular}

${ }^{*} \mathrm{~N} / \mathrm{A}$ This means that there is no available data or the data is missing 
Table 3 Supply of care: Nature of consultation and reference of patients for other French regions and Paris Region

\begin{tabular}{|c|c|c|}
\hline Characteristics & French Regions, $n=4048$ & Paris Region, $n=7294$ \\
\hline Consultations, $n=$ & 13,445 & 36,039 \\
\hline Follow-up & $7463(55.5)$ & $20,560(71.8)$ \\
\hline Global care & $4164(31.0)$ & $9691(33.9)$ \\
\hline Diagnosis & $849(6.3)$ & $3553(12.4)$ \\
\hline Medical act & $838(6.2)$ & $1647(5.7)$ \\
\hline Emergency & $39(0.3)$ & 459 (1.6) \\
\hline Prenatal Diagnosis & $82(0.6)$ & $73(0.2)$ \\
\hline Protocol & $10(0.1)$ & $56(0.2)$ \\
\hline Reference centres, $\mathrm{n}$ & 2 & 4 \\
\hline Competence centres, $\mathrm{n}$ & 34 & 0 \\
\hline \multicolumn{3}{|l|}{ Patients referred by, $n=$} \\
\hline Pediatrician & $1849(45,6)$ & $2986(40.9)$ \\
\hline Other specialist & $843(20.8)$ & $2381(32.6)$ \\
\hline Himself/herself or parents & $323(7.9)$ & $798(10.9)$ \\
\hline Other/unknown & $604(14.9)$ & $748(10.3)$ \\
\hline General practitioner & $184(4.5)$ & $171(2.3)$ \\
\hline Pluridisciplinary prenatal centre & $109(2.7)$ & $99(1.4)$ \\
\hline Association & $62(1.5)$ & $31(0.4)$ \\
\hline Treatment centre & $12(0.3)$ & $48(0.7)$ \\
\hline Geneticist & $22(0.5)$ & $29(0.4)$ \\
\hline Neonatal diagnosis centre & $39(1.0)$ & $1(0.1)$ \\
\hline Mother and child medical centre & $1(0.0)$ & $27(0.4)$ \\
\hline
\end{tabular}

competence centres. The longer the line, the longer the journey for treatment. The thicker the line, the greater the number of patients. This figure is not quantitative, but gives an overview of the care pathways.

We analysed the number of expected and observed patients by French Region, comparing the ratios with the Paris Region (Table 4). This table shows the proportion of patients observed in each French region and the proportion expected if Paris Region was taken as a reference. The ratio of these proportions was then calculated. The closer it is to 1 , the more patients have stayed in their areas for treatment. For the Haute Normandie Region (northern part of France) this ratio was 0.57 . For the Midi-Pyrénées Region (southern part of France, this ratio was 0.03.

The activity of two reference centres, specializing in orofacial diseases and in ENT was studied (Table 5).

We observed the proportion of patients residing outside Paris Region and coming to these centres for treatment for Wiedeman-Beckitwh syndrome, Goldenhar syndrome, Moebius syndrome, Treacher-Collins syndrome, Hypoglossia-hypodactyly syndrome), Binder syndrome, macroglossia (except Wiedemann-Beckwith sydrom, Arhinie and proboscis lateralis, Cleft lip with or without cleft palate and Cleft lip and alveolus/cleft palate.
To give more details on the medical reasons why patients residing outside the Paris Region attend the reference centres of Paris, we observed (Table 6), again by centre (MAFACE and MALO), the distribution of patients residing outside Paris Region and coming to Paris for treatment according to the objective of their consultation.

For Goldenhar syndrome, for example, the proportion of patients not residing in Paris Region but treated in Paris is high $(P=55.5 \%)$. More patients came to have a medical procedure $(P=60.9)$ than to have a diagnosis $(P$ $=38.0 \%$ ). For Moebius syndrome, this proportion was reversed and more patients came for a diagnosis $(P=$ $60.9)$ than for a medical procedure $(P=26.7 \%)$. This was especially true for cysts (Cysts and fistulae of the face and oral cavity/Familial thyroglossal duct cyst/Congenital laryngeal cyst/Nasolacrimal duct cyst) where patients came overwhelmingly for diagnosis $(P=66.7 \%)$ rather than for medical treatment $(P=0)$.

\section{Discussion}

The epidemiological study reported here provides the first information on rare diseases of the head, neck and teeth in terms of public health in France. This is the first time that data from a national database concerning these diseases have been analysed in France. 


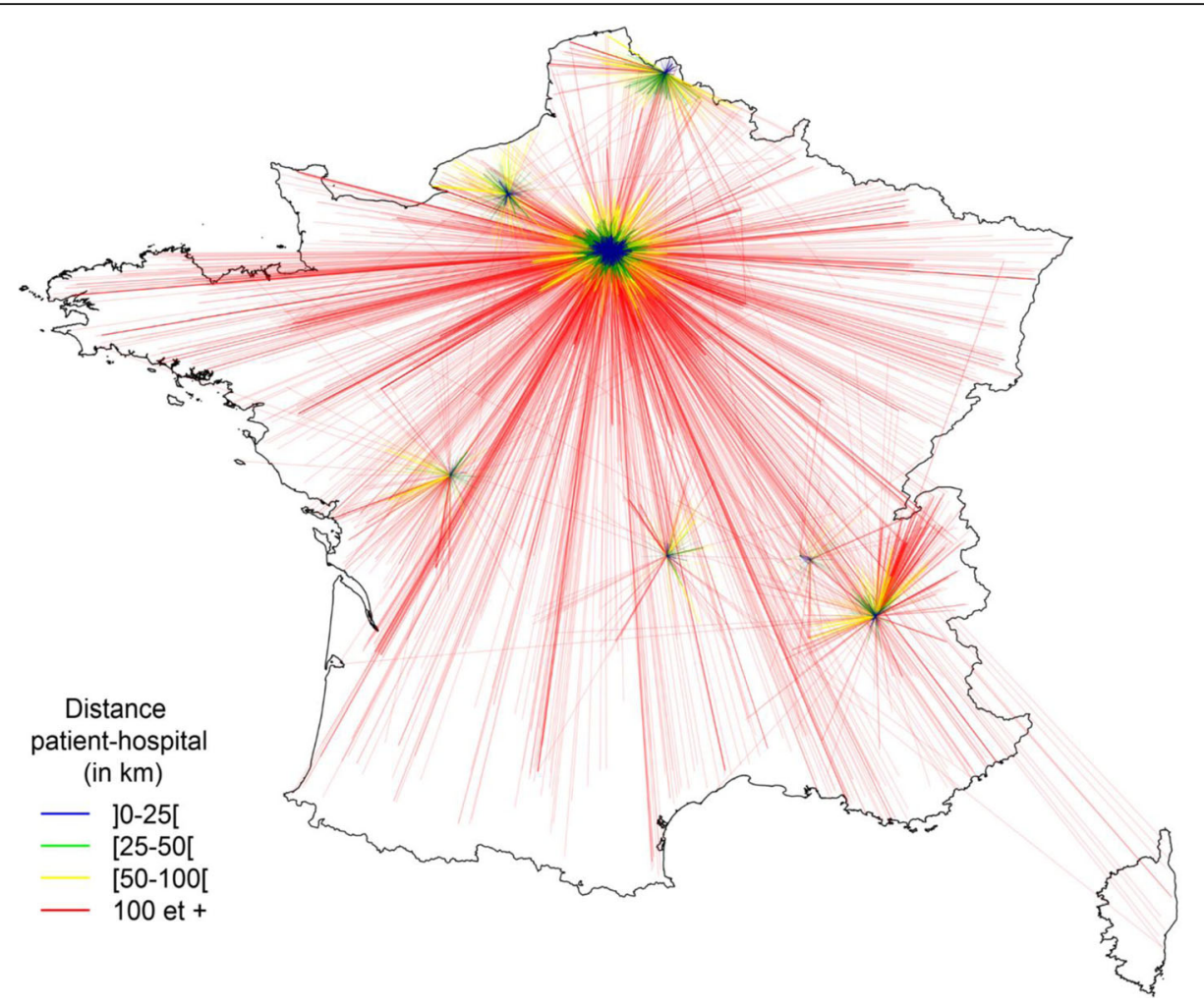

Fig. 2 Average patient-hospital distance traveled by patients (in Km): _ _ ] 0-25 [. — _ 25-50 [. _ ] 50-100 [. _ — 100 and more

This main results show a gap between demand for and supply of care, and reveal how patients travel from their place of residence to the reference centres in Paris with a view to recourse care and management of these very rare diseases.

According to our data, nearly $45 \%$ of all patients resided in Paris Region. This disparity between patients From Paris Region and in other French regions is probably to be explained in part by difficulties experienced by the medical teams in completing the database.

Patients were mostly diagnosed very early or at birth. This is encouraging in terms of the network's ability to meet the patient's need for early management, which is the best guarantee of success in the treatment of these diseases [26]. Early diagnosis does not depend on the centre (regions versus Paris). The clinical entities represented in the cohort are predominantly early-onset ones (oral clefts are becoming better diagnosed using ultrasound since this became a mandatory part of the checklist [27]).

The five most frequent diseases accounted for nearly half of all patients. These most common diseases (oral clefts and Pierre Robin Syndrome) were those treated by the two Paris centres that completed the database the most.

Our study confirmed that cleft lip and alveolus and cleft palate represented the most frequent disease type, as previously reported [28]. In the literature, some diseases (for instance cleft lip and palate) might appear at first sight not to be rare. For example, what was called an "isolated" cleft lip and or/palate could sometimes not be considered as a rare disease (occurring in one in 750 births) [20]. But the so-called "isolated clefts" in fact group together a great number of different phenotypes and aetiologies due to genetic or environmental factors and teratogenic substances, and must be studied in the same way as the syndromic forms in order to be able to count them according to their aetiology [29].

Their frequent appearance has been explained as a product of patient recruitment and because large numbers of them were coded by centres specialising in these diseases [30]. However, prevalence variations for diseases such as oral cleft may be explained by different factors. The use of the term "clefts" as if all these conditions were one phenotype may be considered a mistake. In global terms, isolated palate cleft falls within the definition of "rare" as the global prevalence is less than 1 per 2000. It also differs chronologically, anatomically, epidemiologically, developmentally, in its genetics and environmental risk factors - and in the approach to its management. Cleft Lip and/or Palate segregate separately in pedigrees and do not cross over, so they are absolutely and fundamentally different [31].

As shown in the previous results about "out-of-Parispatients" coming to Paris for care, the finding may signify that a large number of patients were diagnosed in 
Table 4 Expected and observed patients by French Region, with ratio: included cases geography

\begin{tabular}{|c|c|c|c|c|c|c|}
\hline Region & Population & n observed & $\mathrm{n}$ expected & P observed $(/ 10,000)$ & $P$ expected & Ratio \\
\hline Île-de-France & $11,898,502$ & 6642 & 6642 & 5,58 & 5,58 & 1 \\
\hline Alsace & $1,859,869$ & 45 & 1038 & 0,24 & 5,58 & 0,04 \\
\hline Aquitaine & $3,285,970$ & 86 & 1834 & 0,26 & 5,58 & 0,05 \\
\hline Auvergne & $1,354,104$ & 236 & 756 & 1,74 & 5,58 & 0,31 \\
\hline Basse-Normandie & $1,477,209$ & 96 & 825 & 0,65 & 5,58 & 0,12 \\
\hline Bourgogne & $1,641,130$ & 201 & 916 & 1,22 & 5,58 & 0,22 \\
\hline Bretagne & $3,237,097$ & 155 & 1807 & 0,48 & 5,58 & 0,09 \\
\hline Centre & $2,563,586$ & 425 & 1431 & 1,66 & 5,58 & 0,3 \\
\hline Champagne-Ardenne & $1,339,270$ & 176 & 748 & 1,31 & 5,59 & 0,24 \\
\hline Corse & 316,257 & 14 & 177 & 0,44 & 5,6 & 0,08 \\
\hline Franche-Comté & $1,175,684$ & 58 & 656 & 0,49 & 5,58 & 0,09 \\
\hline Guadeloupe & 403,314 & 45 & 225 & 1,12 & 5,58 & 0,2 \\
\hline Guyane & 239,648 & 18 & 134 & 0,75 & 5,59 & 0,13 \\
\hline Haute-Normandie & $1,845,547$ & 584 & 1030 & 3,16 & 5,58 & 0,57 \\
\hline Languedoc-Roussillon & $2,700,266$ & 44 & 1507 & 0,16 & 5,58 & 0,03 \\
\hline Limousin & 738,633 & 35 & 412 & 0,47 & 5,58 & 0,08 \\
\hline Lorraine & $2,349,816$ & 59 & 1312 & 0,25 & 5,58 & 0,04 \\
\hline Martinique & 388,364 & 27 & 217 & 0,7 & 5,59 & 0,12 \\
\hline Midi-Pyrénées & $2,926,592$ & 47 & 1634 & 0,16 & 5,58 & 0,03 \\
\hline Pays de la Loire & $3,632,614$ & 160 & 2028 & 0,44 & 5,58 & 0,08 \\
\hline Picardie & $1,922,342$ & 377 & 1073 & 1,96 & 5,58 & 0,35 \\
\hline Poitou-Charentes & $1,783,991$ & 319 & 996 & 1,79 & 5,58 & 0,32 \\
\hline Provence-Alpes-Côte d'Azur & $4,935,576$ & 96 & 2755 & 0,19 & 5,58 & 0,03 \\
\hline Réunion & 833,944 & 37 & 466 & 0,44 & 5,59 & 0,08 \\
\hline Rhone-Alpes & $6,341,160$ & 791 & 3540 & 1,25 & 5,58 & 0,22 \\
\hline
\end{tabular}

their regional competence and reference centres and then referred to Paris for care and/or follow up. It may therefore show that the Paris Region reference centres have a secondary health care role. It is noticeable in the results that the more specialised the centre, the more it detects and quickly diagnoses the clinical entities. Moreover, as the Paris centres also appear as centres of second resort, delays may sometimes be longer before a confirmed diagnosis is made.

In Paris, most of the medical and non-medical staff in reference centres use the database. This is why we decided to use the Paris data as a proxy to discuss the whole-ofFrance data (in view of the fact that the literature concerned has not shown ecological or environmental variables influencing the diseases studied) [32-34]. This may explain why the prevalence differed between Paris Region and the rest of France.

Prevalences found in the cohort for Paris Region were consistent with those of Orphanet [3], where the most frequent clinical entities were also cleft lip and alveolus, cleft palate, cleft lip and/or palate, vascular anomaly or angioma, isolated Pierre Robin Syndrome and hard palate cleft.

The ratio between proportion observed and proportion expected showed that patients living in the South of France were more apt to travel to be cared for than those living in Haute-Normandie for example.

In some areas such as South of France or Alsace, therefore, low prevalence is likely to be related to nonfulfilment of the database criteria, and may not just occur because patients are leaving their own region to be treated elsewhere. This was also true for the other regions cited. Figure 1 confirms that these regions have competence and reference centres but do not yet have full compliance with the database requirements.

In Paris, reference centres cover rare ENT malformations, Pierre Robin syndrome and congenital deglutitionsuction disorders, dental manifestations of RD, craniosynostosis and craniofacial malformations, and malformations of the face and the oral cavity. Hyper-specialisation of these centres was undoubtedly an attractive feature for patients. This explains how, when diseases are very rare, 
Table 5 Paris Region MAFACE and MALO reference centres (MAFACE, specializing in orofacial diseases and MALO, specializing in ENT) data: attractiveness by disease

\begin{tabular}{lll}
\hline Disease & Patients \% (n) & Out-of Paris Patients \% (n) \\
\hline Wiedemann-Beckwith syndrome & $1.0(90)$ & $33.3(30)$ \\
Goldenhar syndrome & $1.3(117)$ & $55.5(65)$ \\
Moebius & $1.0(83)$ & $56.6(47)$ \\
Treacher-Collins syndrome & $0.6(56)$ & $73.2(41)$ \\
Hypoglossia-hypodactyly syndrome & $0.1(8)$ & $37.5(3)$ \\
Binder syndrome & $0.3(27)$ & $18.5(5)$ \\
macroglossia (except Wiedemann-Beckwith sydrom) & $0.5(44)$ & $29.5(13)$ \\
Arhinie and proboscis lateralis & $0.1(5)$ & $40.0(2)$ \\
Cleft lip with or without cleft palate/Cleft lip and alveolus/cleft palate & $36.1(3094)$ & 32.1 (994) \\
BOR syndrome & $0.6(11)$ & $45.4(5)$ \\
CHARGE syndrome & $0.6(12)$ & $41.7(5)$ \\
Weissenbacher-Zweymuller syndrome & $1.5(27)$ & $29.6(8)$ \\
$\begin{array}{l}\text { Cysts and fistulae of the face and oral cavity/Familial thyroglossal duct } \\
\text { cyst/Congenital laryngeal cyst/Nasolacrimal duct cyst }\end{array}$ & $0.5(9)$ & $22.2(2)$ \\
External auditory canal aplasia/hypoplasia/anotia/microtia & $23.4(425)$ & $42.2(182)$
\end{tabular}

such as Moebius syndrome, patients make the move to seek an expert opinion in Paris reference centres (Table 5). It was observed that the more rare the disease was, the greater the proportion of patients residing outside Paris (for example, for Treacher Collins where the proportion of patients is $P=0.6 \%$, this proportion was $73.2 \%$.) The same distribution has been described for Moebius syndrome. The proportion of patients suffering from this disease was low as recorded in the reference centre $(P=$ $1.0 \%)$, but the proportion of those residing outside Paris Region is close to half of all patients. On the other hand, for oral clefts, which are very well treated in the MAFACE centre, and where the proportion of patients treated there was high, the proportion of patients residing outside Paris Region is lower than for the diseases mentioned above.
"Simplicity" of cases does not necessarily imply higher prevalence. Oral clefts, for example, represent the most important pevalences, all anatomical and syndromic forms combined, nationally and regionally. The therapeutic arsenal can be very complex and sometimes needs to repeat surgeries that have failed, or to re-intervene several times before obtaining a satisfactory result.

However, other determinants of recourse or lack of care, such as inequalities faced by patients in their place of residence, should not be forgotten [35]. Measuring the supply of health care requires different indicators of the medical activity in a geographical unit and, in the case of $\mathrm{RD}$, in reference centres: the establishments, their capacity and specialties, the number of doctors, general practitioners and specialists, nurses, and other

Table 6 By centre (MAFACE, specializing in orofacial diseases and MALO, specializing in ENT), distribution of patients residing outside Paris Region and coming to Paris for treatment per the objective of their consultation

\begin{tabular}{|c|c|c|c|c|c|c|c|}
\hline Center & Disease & $\begin{array}{l}\text { Diagnosis } \\
\%(n)\end{array}$ & $\begin{array}{l}\text { Treatment } \\
\%(\mathrm{n})\end{array}$ & $\begin{array}{l}\text { Follow-up } \\
\%(n)\end{array}$ & $\begin{array}{l}\text { Medical } \\
\text { act } \%(n)\end{array}$ & $\begin{array}{l}\text { Out-of Paris } \\
\text { Global \% } \\
\text { (n) }\end{array}$ & $\begin{array}{l}\text { Global } \\
\text { CENTER } \\
\text { (n) }\end{array}$ \\
\hline \multirow[t]{5}{*}{ MAFACE } & Goldenhar & $38.0(27)$ & $52.6(161)$ & $52.6(300)$ & $60.9(42)$ & $51.2(530)$ & 1016 \\
\hline & Moebius & $60.9(56)$ & $49.5(101)$ & $54.4(241)$ & $26.7(4)$ & $53.3(402)$ & 754 \\
\hline & Treacher-Collins & $75.9(22)$ & $80.3(163)$ & $78.2(248)$ & $71.6(48)$ & $78.1(481)$ & 616 \\
\hline & Van der Woude Syndrome & $20.0(4)$ & $30.1(25)$ & $31.7(97)$ & $34.3(12)$ & $31.1(138)$ & 444 \\
\hline & $\begin{array}{l}\text { Cleft lip with or without cleft palate/Cleft lip and alveolus/cleft } \\
\text { palate }\end{array}$ & $25.6(312)$ & $29.7(1669)$ & $28.5(5297)$ & $31.0(514)$ & $28.8(7792)$ & 27,054 \\
\hline \multirow[t]{4}{*}{ MALO } & BOR syndrome & $66.6(2)$ & $66.7(4)$ & $0(0)$ & $0(0)$ & $46.1(6)$ & 13 \\
\hline & CHARGE Syndrome & $33.3(1)$ & $80.0(4)$ & $20(1)$ & $0(0)$ & $46.1(6)$ & 13 \\
\hline & Weissenbacher-Zweymuller syndrome & $0(0)$ & 25.0 (3) & $29.4(5)$ & $0(0)$ & 27.6 (8) & 29 \\
\hline & $\begin{array}{l}\text { Cysts and fistulae of the face and oral cavity/Familial thyroglossal } \\
\text { duct cyst/Congenital laryngeal cyst/Nasolacrimal duct cyst }\end{array}$ & $66.7(2)$ & 0. (0) & (0) 0 & $0(0)$ & $22.2(2)$ & 9 \\
\hline
\end{tabular}


paramedical professions. It is also necessary to estimate their accessibility and degree of activity. This is what our work did through this particular pathway [36-38].

\section{Strengths}

The research project to exploit the data collected by the database aims, first of all, to obtain some epidemiological estimation of these diseases in France. Analysis of the demand for care and the supply of care, and of the balance between the two, was the primary methodological goal of the exploration of these data. In terms of the organisation of the territorial network of expert centres, the fact that many centres were not in a position to participate in the database meant that the data collected were not yet exhaustive. Indeed, the results obtained for the whole country differed significantly from the figures found in scientific literature, except for the previously discussed cleft palate results for Paris Region. It was for this reason that we made use of the results obtained in Paris Region, which were likely to be closer to epidemiological reality.

In many European countries, federative RD management has been promoted and supported by health ministries and agencies. But France is, with Spain [39], the European country where the organisation of the coverage of RD is the most institutionalised. The data collected can be used as a tool to produce descriptive indicators, but also to assess the fit between health services and needs [40, 41]. This first French national-level study may provide a methodological model for other RD data analysis. It may therefore have important potential for replication for the modelling of other RD health sectors. The reference centres, vetted by the Head, Neck and Teeth network, have received support to deploy human resources with the aim of organising the territorial rare disease network.

In terms of RD institutional organisation, France is a relatively advanced country. The Network improves access to diagnosis, treatment and the provision of highquality healthcare to patients who have conditions requiring a particular concentration of resources or expertise. These concentrations could also be focal points for medical training and research, information dissemination and evaluation, especially for rare diseases.

In the United States, the National Organization for Rare Disorders (NORD) provides information for patients and their families, offers help to patients who cannot afford the required care, and links patients with many patient organisations that provide lists of medical experts. To find out if a particular disease has an organisation, the patient has to search in the NORD's organisational database because there is no national institutional network especially devoted to RD [42-44]. By contrast, Italy was one of the first Member States in the European Union to regulate the field of RD [44]. In Italy, the development of a national plan or strategy for RD derived from the necessity to fulfil the EU Commission Recommendation to adopt national plans or strategies for RD by the end of 2013 [45]. In Spain, the Spanish Rare Diseases Registries Research Network is a project which aims to build a National Rare Diseases Registry based on the input of two different methods: patient outcome research registries and populationbased registries [39].

\section{Limitations}

A good network has been built in the past 8 years, but there are still some pitfalls in the analysis and also apparent issues in the patient health care circuit.

In the database, observational data were not collected for research purposes. This is why we had to deal with limitations and biases such as knowledgeable data users time-varying clinical workflows, using idiosyncratic coding practices, and showing lack of motivation to collect data and misunderstanding of purposes... If centres are not participating in the database, this implies a selection bias that tends to under-estimate the number of patients. It is for this reason that we have taken Paris, whose prevalences are close to literature ones, as a proxy. Analysis for each French Region shows the major differences that appear for many regions, where the fit between supply and demand for care seems to be unsatisfactory (Fig. 1). The ratios between observed and expected numbers calculated for the different French regions compared to Paris Region clearly shows the tendency for patients to come to Paris for their treatment.

Hospital coding for RD, using current coding and classifications systems and practices, tends to underrepresent RD cases. Hospital databases are made to evaluate hospital activity. They are not intended to produce epidemiological data. Indeed, the computer systems currently present in French hospitals do not specify the rarity of clinical entities, and demonstrate the need for specialised databases [46].

To make data comprehensive and achieve exhaustiveness, it will be fruitful to cross-reference the data with additional databases such as the Medical Information Systems Program (MISP) and the National Health Insurance Fund. Patients who have not encountered the care system during the study period, or patients who have been treated for a long time, who are still living and appearing on older databases, might also be included in the registry. In this sense, the development of the BNDMR and the MDS aims to foster communication with computerised hospital care systems, using an anonymous national identifier compatible, technically and legally, with other national databases [35]. 


\section{Conclusions}

Thanks to public policies and local actors, a health network covering the RD problematic from diagnosis through to research has been developed in France in the past ten years. Basic knowledge of a number of clinical entities has increased, but without appreciation of the cumulative weight of these illnesses or of patient care pathways.

At the present time, health care supply and demand are still insufficiently matched. According to the various national plans for rare diseases plans, there are reference and competence centres all over the country. Despite this, some patients are crossing the entire country to seek treatment in Paris. The rarer and more complex the disease, the more expert advice will be solicited. Hyper-specialisation of care, lack of patient information, and a deficit of resources in some centres may be elements contributing to adverse impacts on patients' quality of life and to the heavy economic and social burdens borne by patients and their families.

Further coordination and improvement of the country-wide care network will be needed to fulfil the objective of impacting positively on the daily lives of patients. This study summarises the present situation, as a first landmark in this national-scale process, with the first confident estimations of frequencies in the French population of cleft palate, the most notable orofacial rare malformation.

\section{Additional file}

Additional file 1: Reference and competence centres for the Head, Neck and Teeth French Rare Diseases Network. (DOCX 27 kb)

\section{Abbreviations}

BNDMR: French rare diseases repository; CEMARA: Rare disease data bank: MDS: Minimal data set; RD: Rare disease

\section{Acknowledgements}

The authors wish to thank the members of the Head, Neck and Teeth French Rare Diseases Network: all the medical and non-medical staff in competence and reference centres. The authors also wish to thank the members of the platform on these rare diseases: François Lecardonnel, Audrey Legrand, Jessica Chaloyard, Lucie Jourdan.

\section{Funding}

One funding/research grant was received to support this study from University Paris-Diderot (Action Structurante Dental faculty Garancière).

\section{Availability of data and materials}

The datasets during and/or analysed during the current study are available from the corresponding author on reasonable request.

\section{Authors' contribution}

Conception and design: LF, RC, CA. Analysis and interpretation: LF. Data collection: CM, AR, MC. Writing the article: LF, MM, CA. Critical revision of the article: LF, MM, AR, AB, RC, CA, MPV, EG. Final approval of the article: LF, MM, $A B, R C, C A, E G, M P V$. Statistical analysis: LF, CM, CA. Overall responsibility: LF. All authors read and approved the final manuscript.

\section{Competing interests}

The authors declare that they have no competing interests.

\section{Consent for publication}

Not applicable.

Ethics approval and consent to participate

Ethical approval for the study was obtained from the Ethics Committee of the BNDMR. Consent was obtained from all participants when coded in the database. Database was fully provided by the staff member.

\section{Publisher's Note}

Springer Nature remains neutral with regard to jurisdictional claims in published maps and institutional affiliations.

\section{Author details}

${ }^{1}$ Université Paris Diderot - Sorbonne Paris Cité, INSERM, Laboratoire ECEVE UMR1123, Paris, France. ${ }^{2}$ Centre de référence des malformations rares de la face et de la cavité buccale, Hôpital Rothschild, AP-HP, Paris, France. ${ }^{3}$ Banque Nationale de Données Maladies Rares, Hôpital Necker Enfants Malades, AP-HP, Paris, France. ${ }^{4}$ Centre de référence des malformations rares de la face et de la cavité buccale, Hôpital Necker, AP-HP, Paris, France. ${ }^{5}$ Université Paris Descartes-Sorbonne Paris Cité, Paris, France. ${ }^{6}$ Service de chirurgie maxillo-faciale et de chirurgie plastique, Hôpital Necker, AP-HP, Paris, France. ${ }^{7}$ Filière de santé maladies rares TETECOU: malformations rares de la tête, du cou et des dents, Hôpital Necker, Paris, France. ${ }^{8}$ Université Paris Diderot Sorbonne Paris Cité, INSERM, Laboratoire de physiopathologie orale et moléculaire, UMRS 1138, Paris, France. ${ }^{9}$ INSERM UMR_S1163 Bases moléculaires et physiopathologiques des ostéochondrodysplasies, Institut Imagine, Necker, Paris, France.

Received: 30 March 2017 Accepted: 11 May 2017

Published online: 19 May 2017

References

1. Richter T, Nestler-Parr S, Babela R, Khan ZM, Tesoro T, Molsen E, HDIS for P and ORRDSIG. Rare Disease Terminology and Definitions-A Systematic Global Review: Report of the ISPOR Rare Disease Special Interest Group.

2. Boycott KM. Depth of the rare genetic diseases: strategies to identify the remaining genes and diseases. Pathology. 2016;48. http://www.nature.com/ doifinder/10.1038/ejhg.2016.146.

3. Orphanet Report Series - Prevalence of rare diseases: Bibliographic data November 2016 - Number 1 http://www.orpha.net/orphacom/cahiers/docs/ GB/Prevalence_of_rare_diseases_by_alphabetical_list.pdf. 2016.

4. de La Dure-Molla M, Philippe Fournier B, Berdal A. Isolated dentinogenesis imperfecta and dentin dysplasia: revision of the classification. Eur J Hum Genet [Internet]. 2015 [cited 2017 Jan 2];23:445-51. Available from: http:// www.nature.com/doifinder/10.1038/ejhg.2014.159

5. Kortelainen T, Tolvanen M, Luoto A, Ylikontiola LP, Sándor GK, Lahti S. Comparison of Oral Health-Related Quality of Life Among Schoolchildren With and Without Cleft Lip and/or Palate. Cleft PalateCraniofacial J [Internet]. 2016 [cited 2016 Nov 3];53:e172-6. Available from: http://www.cpcjournal.org/doi/10.1597/14-180

6. Medio $M$, de la Dure Molla M. Treatment of infra-occluded primary molars in patients with dental ageneses. Int Orthod [Internet]. 2014 [cited 2017 Jan 2];12:291-302. Available from: http://linkinghub.elsevier. com/retrieve/pii/S1761722714000503

7. Hadj Said M, Foletti JM, Graillon N, Guyot L, Chossegros C. Orofacial manifestations of scleroderma. A literature review. Rev Stomatol Chir Maxillofac Chir Orale [Internet]. 2016 [cited 2016 Nov 5];117:322-6. Available from: http://linkinghub.elsevier.com/retrieve/pii/S2213653316300453

8. Broder HL, Wilson-Genderson M, Sischo L. Oral health-related quality of life in youth receiving cleft-related surgery: self-report and proxy ratings. Qual Life Res [Internet]. 2016 [cited 2016 Nov 3]; Available from: http://www.ncbi. nlm.nih.gov/pubmed/27699557

9. Schönmeyr B, Wendby L, Sharma M, Jacobson L, Restrepo C, Campbell A. Speech and Speech-Related Quality of Life After Late Palate Repair: A Patient's Perspective. J Craniofac Surg [Internet]. 2015 [cited 2016 Nov 3];26: 1513-6. Available from: http://www.ncbi.n/m.nih.gov/pubmed/26114520

10. Stock NM, Feragen KB. Psychological adjustment to cleft lip and/or palate: A narrative review of the literature. Psychol Health [Internet]. 2016 [cited 2016 
Nov 3];31:777-813. Available from: http://www.tandfonline.com/doi/full/10 1080/08870446.2016.1143944

11. Woincham LN, Kruger E, Tennant M. A retrospective audit of population service access trends for cleft lip and cleft palate patients. Community Dent Health [Internet]. 2015 [cited 2017 Feb 8];32:237-40. Available from: http:// www.ncbi.nlm.nih.gov/pubmed/26738222

12. Long RE, Wilson-Genderson M, Grayson BH, Flores R, Broder HL. Oral Health-Related Quality of Life and Self-Rated Speech in Children With Existing Fistulas in Mid-Childhood and Adolescence. Cleft Palate. Craniofac J [Internet]. 2015 [cited 2016 Jul 11]; Available from: http:// www.ncbi.nlm.nih.gov/pubmed/26437081

13. Ahmed B, Farshad AF, Yazdanie N. Rehabilitation of a large maxillo-facial defect using acrylic resin prosthesis. J Coll Physicians Surg Pak [Internet]. 2011 [cited 2016 Oct 26];21:254-6. Available from: http://www.ncbi.nlm.nih. gov/pubmed/21453630

14. Chiumariello S, Del Torto G, Guarro G, Alfano C. The role of plastic surgeon in complex cephalic malformations. Our experience. Ann Ital Chir [Internet]. [cited 2016 Oct 26];85:166-70. Available from: http://www.ncbi.nlm.nih.gov/ pubmed/24901536

15. Clauss F, Waltmann E, Barriere P, Hadj-Rabia S, Manière M-C, Schmittbuhl M. Dento-maxillo-facial phenotype and implants-based oral rehabilitation in Ectodermal Dysplasia with WNT10A gene mutation: report of a case and literature review. J Craniomaxillofac Surg [Internet]. 2014 [cited 2016 Oct 26]; 42:e346-51. Available from: http://www.ncbi.nlm.nih.gov/pubmed/24702986

16. Berg E, Haaland ØA, Feragen KB, Filip C, Vindenes HA, Moster D, et al. Health Status Among Adults Born With an Oral Cleft in Norway. JAMA Pediatr [Internet]. 2016 [cited 2016 Nov 3]; Available from: http://archpedi. jamanetwork.com/article.aspx?doi=10.1001/jamapediatrics.2016.1925

17. Beluci ML, Genaro KF. Quality of life of individuals with cleft lip and palate preand post-surgical correction of dentofacial deformity. Rev da Esc Enferm da USP [Internet]. 2016 [cited 2016 Nov 3];50:217-23. Available from: http://www. scielo.br/scielo.php?script=sci_arttext\&pid=S0080-62342016000200217\&lng= en\&nrm=iso\&tlng=en

18. Guerrero CA. Cleft lip and palate surgery: 30 years follow-up. Ann Maxillofac Surg [Internet]. 2012 [cited 2016 Jul 11];2:153-7. Available from: http:/www. ncbi.nlm.nih.gov/pubmed/23483117

19. Mossey P. Epidemiology underpinning research in the aetiology of orofacial clefts. Orthod Craniofac Res [Internet]. 2007 [cited 2016 Dec 18];10:114-20. Available from: http://www.ncbi.nlm.nih.gov/pubmed/17651127

20. Doray B, Badila-Timbolschi D, Schaefer E, Fattori D, Monga B, Dott B, et al. [Epidemiology of orofacial clefts (1995-2006) in France (Congenital Malformations of Alsace Registry)]. Arch Pediatr [Internet]. 2012 [cited 2015 Oct 26];19:1021-9. Available from: http://www.ncbi. nlm.nih.gov/pubmed/22925539

21. La politique nationale de labellisation. [cited 2016 Dec 20]; Available from: http://www.orpha.net/orphacom/cahiers/docs/FR/Liste_des_centres_de_ reference_labellises_region.pdf

22. Landais P, Messiaen C, Rath A, Le Mignot L, Dufour E, Ben Said M, et al. CEMARA an information system for rare diseases. Stud Health Technol Inform [Internet]. 2010 [cited 2016 Jun 1];160:481-5. Available from: http:// www.ncbi.n/m.nih.gov/pubmed/20841733

23. Choquet R, Maaroufi M, de Carrara A, Messiaen C, Luigi E, Landais P. A methodology for a minimum data set for rare diseases to support national centers of excellence for healthcare and research. J Am Med Inform Assoc [Internet]. 2015 [cited 2015 Oct 5];22:76-85. Available from: http://www.ncbi. nlm.nih.gov/pubmed/25038198

24. Choquet R, Maaroufi M, Fonjallaz Y, de Carrara A, Vandenbussche P-Y, Dhombres $F$, et al. LORD: a phenotype-genotype semantically integrated biomedical data tool to support rare disease diagnosis coding in health information systems. AMIA Annu Symp Proc [Internet]. 2015 [cited 2016 Jun 1]; 2015:434-40. Available from: http://www.ncbi.nlm.nih.gov/pubmed/26958175

25. Messiaen C, Le Mignot L, Rath A, Richard J-B, Dufour E, Ben Said M, et al, CEMARA: a Web dynamic application within a N-tier architecture for rare diseases. Stud Health Technol Inform [Internet]. 2008 [cited 2016 Jun 1];136: 51-6. Available from: http://www.ncbinlm.nih.gov/pubmed/18487707

26. Dissaux C, Bodin F, Grollemund B, Bridonneau T, Kauffmann I, Mattern J-F, et al. Evaluation of success of alveolar cleft bone graft performed at 5 years versus 10 years of age. J Cranio-Maxillofacial Surg [Internet]. 2016 [cited 2016 Dec 18]; 44:21-6. Available from: http://www.ncbi.nlm.nih.gov/pubmed/26646636

27. James JN, Schlieder DW. Prenatal Counseling, Ultrasound Diagnosis, and the Role of Maternal-Fetal Medicine of the Cleft Lip and Palate Patient. Oral
Maxillofac. Surg Clin North Am [Internet]. 2016 [cited 2017 Feb 22];28:14551. Available from: http://www.ncbi.nlm.nih.gov/pubmed/26928557

28. Sæle P, Østhus E, Ådalen S, Nasir EF, Mustafa M. Pattern of clefts and dental anomalies in six-year-old children: a retrospective observational study in western Norway. Acta Odontol Scand [Internet]. 2016 [cited 2016 Dec 18];16. Available from: http://www.ncbi.nlm.nih.gov/pubmed/27897086

29. McBride WA, Mclntyre GT, Carroll K, Mossey PA. Subphenotyping and Classification of Orofacial Clefts: Need for Orofacial Cleft Subphenotyping Calls for Revised Classification. Cleft Palate. Craniofac J [Internet]. 2016 [cited 2017 Jan 27]; 53:539-49. Available from: http://www.cpcjournal.org/doi/10.1597/15-029

30. Dissaux C, Grollemund B, Bodin F, Picard A, Vazquez M-P, Morand B, et al. Evaluation of 5-year-old children with complete cleft lip and palate: Multicenter study. Part 2: Functional results. J Cranio-Maxillofacial Surg [Internet]. 2016 [cited 2016 Dec 18];44:94-103. Available from: http://www. ncbi.nlm.nih.gov/pubmed/26712484

31. Luijsterburg AJM, Rozendaal AM, Vermeij-Keers C. Classifying common oral clefts: a new approach after descriptive registration. Cleft Palate Craniofac J [Internet]. 2014 [cited 2017 Jan 27];51:381-91. Available from: http://www. cpcjournal.org/doi/abs/10.1597/12-088

32. Calzolari E, Milan M, Cavazzuti GB, Cocchi G, Gandini E, Magnani C, et al. Epidemiological and genetic study of 200 cases of oral cleft in the Emilia Romagna region of northern Italy. Teratology [Internet]. 1988 [cited 2017 Jan 6];38:559-64. Available from: http://www.ncbi.nlm.nih.gov/pubmed/3238612

33. Salihu S, Krasniqi B, Sejfija O, Heta N, Salihaj N, Geci A, et al. Analysis of Potential Oral Cleft Risk Factors in the Kosovo Population. Int Surg [Internet]. 2014 [cited 2017 Jan 6];99:161-5. Available from: http://www.ncbi.nlm.nih. gov/pubmed/24670027

34. Kianifar HH, Hasanzadeh N, Jahanbin A, Ezzati A, Kianifar HH. Cleft lip and Palate: A 30-year Epidemiologic Study in North-East of Iran. Iran J Otorhinolaryngol [Internet]. 2015 [cited 2017 Jan 6];27:35-41. Available from: http://www.ncbi.nlm.nih.gov/pubmed/25745610

35. Taruscio D, Gentile AE, Evangelista T, Frazzica RG, Bushby K, Montserrat AM. Centres of Expertise and European Reference Networks: key issues in the field of rare diseases. The EUCERD Recommendations. Blood Transfus [Internet]. 2014 [cited 2015 Jul 15];12 Suppl 3:s621-5. Available from: http:// www.pubmedcentral.nih.gov/articlerender.fcgi?artid=4044812\&tool= pmcentrez\&rendertype $=$ abstract

36. Bellanger MM, Jourdain A. Tackling regional health inequalities in france by resource allocation: a case for complementary instrumental and processbased approaches? Appl Health Econ Health Policy [Internet]. 2004 [cited 2016 Nov 24];3:243-50. Available from: http://www.ncbi.nlm.nih.gov/ pubmed/15901198

37. Occelli F, Deram A, Génin M, Noël C, Cuny D, Glowacki F. Mapping EndStage Renal Disease (ESRD): Spatial Variations on Small Area Level in Northern France, and Association with Deprivation. Reboldi G, editor. PLoS One [Internet]. 2014 [cited 2016 Nov 24];9:e1 10132. Available from: http://dx. plos.org/10.1371/journal.pone.0110132

38. Bettencourt LMA, Lobo J. Urban scaling in Europe. J R Soc Interface [Internet]. 2016 [cited 2016 Nov 24];13:20160005. Available from: http://rsif. royalsocietypublishing.org/lookup/doi/10.1098/rsif.2016.0005

39. de la Paz M, Alonso V, Zurriaga O, Astray J, Aldana-Espinal J, Margolles M, et al. National Rare Disease Registries: overview from Spain. Orphanet J Rare Dis [Internet]. BioMed Central; 2014 [cited 2016 Nov 19];9:O8. Available from: http://ojrd.biomedcentral.com/articles/10.1186/1750-1172-9-S1-08

40. Kole A, Faurisson F. Rare diseases social epidemiology: analysis of inequalities. Adv Exp Med Biol [Internet]. 2010 [cited 2016 Jun 1];686:22350. Available from: http://www.ncbi.nlm.nih.gov/pubmed/20824449

41. Denis A, Mergaert L, Fostier C, Cleemput I, Simoens S. A comparative study of European rare disease and orphan drug markets. Health Policy [Internet]. 2010 [cited 2016 Jul 27];97:173-9. Available from: http://www.ncbinlm.nih. gov/pubmed/20800761

42. Vittozzi L, Gainotti S, Mollo E, Donati C, Taruscio D. A model for the European platform for rare disease registries. Public Health Genomics [Internet]. 2013 [cited 2016 Jul 27];16:299-304. Available from: http://www. ncbi.nlm.nih.gov/pubmed/24503590

43. National plans or strategies for rare diseases - European Commission [Internet]. Available from: http://ec.europa.eu/health/rare_diseases/national_ plans/detailed/index_en.htm

44. Congiu ME. The Italian National Plan for Rare Diseases. Blood Transfus [Internet]. 2014 [cited 2016 Jul 27];12 Suppl 3:s614-6. Available from: http://www.ncbi.nlm.nih.gov/pubmed/24922302 
45. Taruscio D, Mollo E, Gainotti S, Posada de la Paz M, Bianchi F, Vittozzi L. The EPIRARE proposal of a set of indicators and common data elements for the European platform for rare disease registration. Arch Public Health [Internet]. BioMed Central; 2014 [cited 2015 Jul 12];72:35. Available from: http://www. ncbi.nlm.nih.gov/pubmed/25352985

46. Aymé S, Bellet B, Rath A. Rare diseases in ICD11: making rare diseases visible in health information systems through appropriate coding. Orphanet J Rare Dis [Internet]. 2015 [cited 2016 Jun 1];10:35. Available from: http:/www.ncbi. nlm.nih.gov/pubmed/25887186

Submit your next manuscript to BioMed Central and we will help you at every step:

- We accept pre-submission inquiries

- Our selector tool helps you to find the most relevant journal

- We provide round the clock customer support

- Convenient online submission

- Thorough peer review

- Inclusion in PubMed and all major indexing services

- Maximum visibility for your research

Submit your manuscript at www.biomedcentral.com/submit 